\title{
Integration of Value Stream Map and Healthcare Failure Mode and Effect Analysis into Six Sigma Methodology to Improve Process of Surgical Specimen Handling
}

\author{
Sheng-Hui Hung, MS ${ }^{1}$, Pa-Chun Wang, MD, MSc.,MBA ${ }^{2}$, Hung-Chun Lin, PhD \\ IEEM $^{3}$, Hung-Ying Chen, MIEEM ${ }^{3}$ and Chao-Ton Su, PhD IE $^{3^{*}}$ \\ ${ }^{1}$ Department of Quality Management Center, Cathay General Hospital, \\ Taipei, Taiwan. \\ ${ }^{1}$ Institute of health policy and management, National Taiwan University, \\ Taipei, Taiwan. \\ ${ }^{2}$ Department of Quality Management Center, Cathay General Hospital, \\ Taipei, Taiwan. \\ ${ }^{3}$ Department of Industrial Engineering and Engineering Management, National Tsing \\ Hua University, Hsinchu, Taiwan.
}

Submitted March 2015. Accepted for publication June 2015.

\begin{abstract}
Specimen handling is a critical patient safety issue. Problematic handling process, such as misidentification (of patients, surgical site, and specimen counts), specimen loss, or improper specimen preparation can lead to serious patient harms and lawsuits. Value stream map (VSM) is a tool used to find out non-value-added works, enhance the quality, and reduce the cost of the studied process. On the other hand, healthcare failure mode and effect analysis (HFMEA) is now frequently employed to avoid possible medication errors in healthcare process. Both of them have a goal similar to Six Sigma methodology for process improvement. This study proposes a model that integrates VSM and HFMEA into the framework, which mainly consists of define, measure, analyze, improve, and control (DMAIC), of Six Sigma. A Six Sigma project for improving the process of surgical specimen handling in a hospital was conducted to demonstrate the effectiveness of the proposed model.
\end{abstract}

Keywords: value stream map, HFMEA, Six Sigma, surgical safety

${ }^{*}$ Corresponding author: Chao-Ton Su, Department of Industrial Engineering and Engineering Management, National Tsing Hua University, 101, Section 2 Kuang Fu Road, Hsinchu 30013, Taiwan. Phone: +886-35742936. E-mail: ctsu@mx.nthu.edu.tw. Other authors: angel@cgh.org.tw; drtony@seed.net.tw; d9534801@oz.nthu.edu.tw; kobe770716@yahoo.com.tw. 


\section{INTRODUCTION}

\subsection{Six Sigma, Value Stream Map and Healthcare Failure Mode and Effect} Analysis

Many researchers have focused on the application of Six Sigma methodology to improve healthcare quality and safety of patients [1-3]. Six Sigma is a project- and customer-driven approach that aims to reduce variation and cost, thereby enhancing the quality of a product or process and customer satisfaction. Six Sigma improvement projects are implemented by a well-structured approach that consists of five phases, namely, define, measure, analyze, improve, and control (DMAIC) [4]. Recently, some researchers and practitioners integrated additional effective techniques to strengthen the Six Sigma methodology [5,6]. Value stream map (VSM) is a tool used to explore the waste location in a process; thus, improvement plans can be developed to enhance the efficiency of a process [7]. Healthcare failure mode and effect analysis (HFMEA) is also a tool that is frequently employed to identify the risk in advance and prevent the occurrence of possible errors in the medication process [8]. Both VSM and HFMEA could help Six Sigma to achieve high customer satisfaction in the healthcare process [9].

This study presents a model that incorporates VSM and HFMEA into the DMAIC for healthcare process. To illustrate the effectiveness of the proposed model, a Six Sigma project was conducted to improve the process of surgical specimen acquisition in a hospital.

\subsection{Handling Process of Surgical Specimens}

Pathology reports of patients are crucial information for doctors to make a diagnosis. Surgical specimen collection, handling and transportation represent important patient safety concerns [10]. Specimen misidentification was noted in several studies, around $0.1-5 \%$ of cases in a modern pathology laboratory $[11,12]$.

Raouf and Nakhleh [13] described how errors occur in surgical pathology, including general factors of variable input, complexity, inconsistency, time constraints, hand-off and inflexible hierarchical culture. Specimen rejection by the pathology department or failure to transport the specimens on time to the pathology department for examination can decrease diagnosis accuracy and may put patients at risk. Moreover, the cost of specimen re-collection can increase because of the delay in time. Lost specimen is regarded as a critical medical malpractice. These undesired incidents may lead to situations where patients need to endure the pain of a second surgery and medical personnel need to deal with specimen rejection [10,14-16]. These situations can increase non-value-added (NVA) works, reduce healthcare quality and confidence of patients to hospitals, damage hospital reputation, and even result in a great amount of compensation for patients. Therefore, specimen handling is an important and high-risk process in hospitals. Proper collection, preservation, and transportation of specimens and efficient reduction of specimen rejection rates are important issues in healthcare.

The present case study was conducted in a hospital located in Taipei, Taiwan. This hospital is a reputable medical center and has served the community and people of northern Taiwan for more than 30 years. A total of 19,890 specimens were collected in 


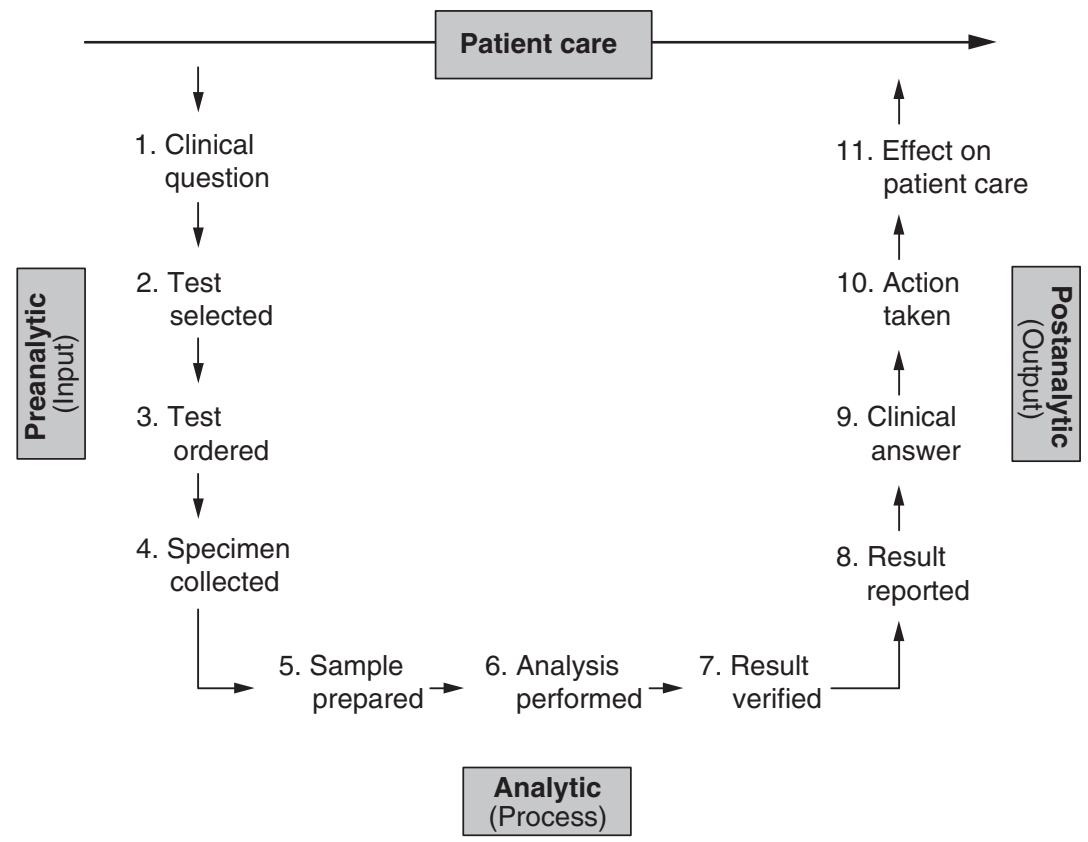

Figure 1. Laboratory testing process of patient care from the beginning to the end [7].

the hospital in 2010. Among these specimens, 182 were rejected. The specimen rejection rate was $0.92 \%$. To improve surgery safety and to reach the goal of zero rejection of specimen, the hospital implemented a Six Sigma project. By doing so, the hospital also expected to reduce risks, lower costs, and enhance the safety of specimen collection and transportation process.

The total testing process of patient care from the beginning to the end is divided into three phases, namely, pre-analytical, analytical, and post-analytical (Figure 1) $[17,18]$. According to Wiwanitkit's analysis [19], most testing errors occur in the pre-analytical phase, accounting for $84.5 \%$ of the total errors detected. These errors mostly occur because of inaccurate process of specimen collection and transportation. Ninety-three percent of specimen errors are attributed to the lack of standard operating procedure for collecting and transporting specimen, including patient preparation and collection, handling, and specimen storage [20].

\section{METHODS}

\subsection{Six Sigma Methodology}

Six Sigma was originally designed to improve manufacturing process. Usually, Six Sigma starts with the deployment of business strategies, after which several important Six Sigma projects are generated, and then the DMAIC is employed to improve the key process. Over the past decade, Six Sigma has become one of the most adopted and recognized approaches for quality improvement in many industry sectors [21-23]. 
A structural approach that integrated Six Sigma and Total Quality Management and continuous quality improvement to improve the quality of patient care was reported [24]. Feng and Antony [4] integrated the data envelopment analysis into each phase of DMAIC to improve the efficiency measure in healthcare service, thereby optimizing and enhancing resource planning and financial revenue in the long term. All the aforementioned applications suggest that innovative combinations of Six Sigma methodology and other approaches can be the key to the success.

\subsection{Value Stream Map}

Value stream map (VSM) is a visual, simple, but powerful tool and an important component of a Lean production system. In VSM, a few efficiency indexes of process operation are used to compare the efficiency or estimate the waste between different processes. Process cycle efficiency (PCE) is often used and described as follows:

$$
\mathrm{PCE}=\frac{\mathrm{VA} \text { time }}{\text { total lead time }}
$$

where VA time, value-added time, is the necessary activity time for products or services based on customer's viewpoint. Total lead time is the time spent from the beginning to the end of the whole process.

In recent years, VSM has attracted the attention of the healthcare community. Several researchers used VSM to optimize clinical workflows and improve the efficiency of healthcare process. Grove et al. [25] utilized VSM and revealed that $65 \%$ of the subprocesses in the visiting service process are waste in the National Health Service of UK, and the project team then redesigned a new process map to remove the waste works. A previous study [26] listed five major benefits of using VSM and used them to develop a system mapping and analysis method for Bozeman Deaconess Hospital. Through that method, the managers can visualize and better understand the medication delivery system and reduce waste from a systematic perspective. Carter et al. [27] developed a Lean improvement program, including the use of VSM, to improve the clinical operations at Komfo Anokye Teaching Hospital in Ghana. They also used the program to identify the eight lessons learned to aid future global emergency medicine system initiatives for low- to middle-income countries. These studies suggest that VSM is a helpful and workable tool to reduce waste and enhance process efficiency.

\subsection{Healthcare Failure Mode and Effect Analysis (HFMEA)}

In 1998, the US Veterans Administration National Centre for Patients Safety developed the HFMEA method based on its own root cause analysis program and the US Food and Drug Administration's Hazard Analysis and Critical Control Point tool [28-30]. In 2000, the US Joint Commission on Accreditation of Healthcare Organization (JCAHO) recommended HFMEA in healthcare process analysis to avoid possible medication errors. After 2002, JCAHO began to request its affiliated medical institutions for analyses of high-risk medical processes every year [31]. Thereafter, anticipative risk analysis has been generalized in medical processes $[32,33]$. 
In 2012, Cheng et al. adopted HFMEA to identify potential chemotherapy process failures [34]. Several actions was implemented to reduce medication errors in the process of drug prescription, validation and dispensing [35]. Kuo et al. extended HFMEA to explore the impacts of geriatric outpatient service process failures on elderly patients. Moreover, HFMEA was employed to reduce the probability of failure in the oral chemotherapy order, review and administration process in order to reduce oral chemotherapy-related prescribing errors [36,37].

To conduct an HFMEA procedure, five main steps are adopted and described as follows:

1. Define the HFMEA topic.

2. Assemble the team.

Our team members include chief and head nurse of operating room, surgeon, nurse practitioner, leader of pathology department, leader of information technology, quality manager of quality management center.

3. Describe the process graphically.

4. Conduct a hazard analysis.

For each sub-process, all potential failure modes are listed and illustrated. The severity and probability of the listed possible failure modes are determined based on pre-set criteria. The severity score is used to measure the levels of potential failures that can negatively affect patients or patient care, in terms of four degrees: catastrophic (4 points), major (3 points), moderate ( 2 points), and minor (1 point). The probability score is used to evaluate the frequency of possible failure. Based on the definitions in a previous report from the National Centre for Patient Safety in 2001, this score is rated as follows: frequent (several times in 1 year, 4 points), occasional (several times in 2 years, 3 points), uncommon (sometimes in 2 years to 5 years, 2 points), and remote (sometimes in 5 years to 30 years, 1 point). The scores of severity and probability are multiplied together to obtain the hazard score. By considering the hazard score and criticality, controllability, and detectability, a HFMEA decision tree is generated to help determine the actions of improvement to be taken in the succeeding steps.

5. Define actions and outcome measures.

\subsection{Integration of VSM and HFMEA into Six Sigma Methodology}

A project can be faultlessly executed from define phase to control phase using Six Sigma methodology. Various suitable tools are available for each phase of the DMAIC model to facilitate smooth project implementation. Although VSM and HFMEA have been applied in many areas, this study tries to demonstrate that healthcare professionals could enhance the usefulness of Six Sigma and deliver better healthcare service (through reducing medical errors and processing time) with the incorporation of VSM and HFMEA. The integrated DMAIC structure is shown in Table 1. The proposed method is expected to reduce risks, lower costs, and enhance the safety of specimen collection and transportation process in hospitals. In addition, this model is expected to benefit implementation of Six Sigma in terms of the following: (1) providing measure 
Table 1. VSM and HFMEA in the DMAIC structure

\begin{tabular}{lll}
\hline DMAIC phases & Main contents in each phase & Supplementaries \\
\hline Define & $\bullet$ Project charter & \\
& $\bullet$ & \\
& Determining customers and their & \\
& $\bullet$ High level process map & \\
\hline Measure & $\bullet$ Measure system analysis & \\
& $\bullet$ Data collection plan & • Create a VSM \\
\hline Analyze & $\bullet$ Measuring the current status & $\bullet$ VSM-value stream analysis \\
& $\bullet$ Pata analysis & $\bullet$ HFMEA-describe the process \\
& $\bullet$ HFMEA-conduct a hazard analysis \\
\hline Improve & Generating improvement ideas & $\bullet$ HFMEA-actions and outcome \\
& and solutions & measures \\
\hline Control & Pilot test & \\
& Establishing the standard operating & \\
& procedure & \\
\hline
\end{tabular}

and analysis tools to reduce waste and prevent risk, (2) evaluating each step of all processes and sub-processes to avoid neglecting the information which is not obtained from the data analysis, (3) being able to analyze each sub-process based on experiences of participating departments through the regular discussion in the cross-sectoral team, and (4) being able to systematically and structurally analyze the problem and reduce unnecessary steps to make the managerial approval of the improvement solutions easy.

\section{RESULTS}

This study was reviewed and granted a waiver by the Institutional Review Board of the Cathay General Hospital, Taipei, Taiwan.

\subsection{Define Phase}

Based on the Pareto principle introduced by Vilfredo Pareto and applied by Joseph Juran to Quality Management methodology, the project team focused on the specimens collected from surgical and clinical surgeries, which accounted for most of the specimens submitted for testing in the hospital. After a thorough investigation with the medical personnel of the hospital, the project team identified the primary issues. Team members analysed the surgical specimen collection and transportation processes by qualifying and quantifying the voice and demand of the internal and external customers before setting the output measurement indicators and targets (Table 2). Table 2 shows that the important characteristics related to the process of specimen collection and 


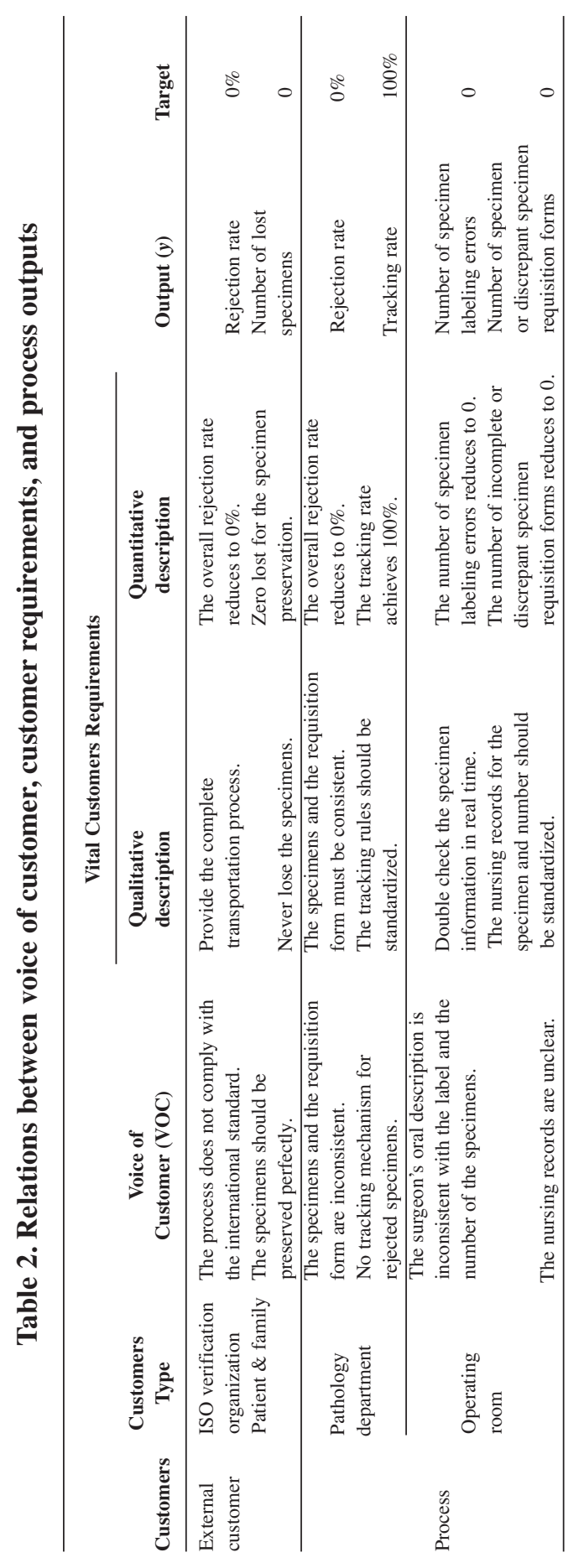




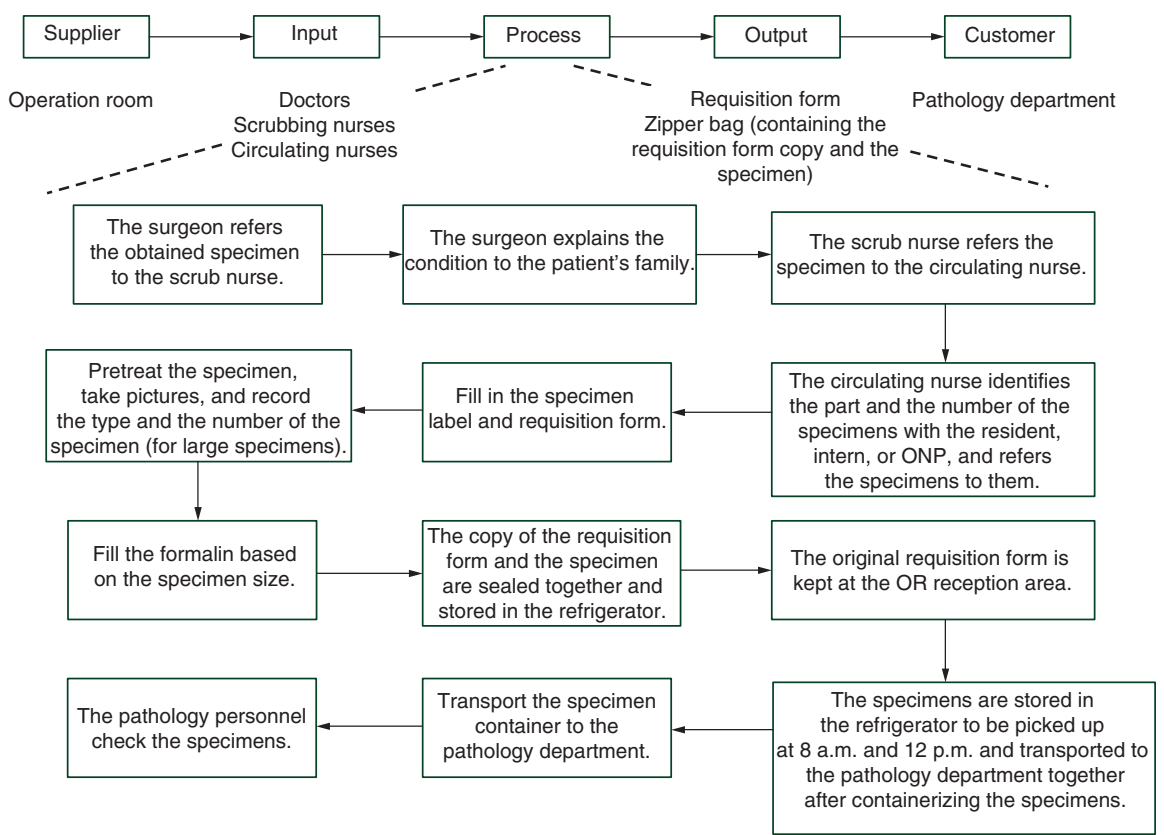

Figure 2. Scope of the project

transportation include rejection rate, number of lost specimens, specimen labeling errors, and incomplete or discrepant specimen requisition form. Figure 2 illustrates a high-level process map that can provide the visualization of the process. In Six Sigma implementation, we usually use a high-level process map SIPOC (Supplier-InputProcess-Output-Customer) diagram to better understand a process and to identify the project scope. By using SIPOC diagram, we develop a macro point of view, and allow gradual addition of detailed thoughts based on the diagram.

\subsection{Measure Phase}

Table 3 shows the operation definitions of the process outputs $(y)$. To ensure the accuracy of the data analysis, the consistency of the measurement system must be confirmed before the measurement procedure. Given that the number of the rejected surgical pathology specimens belongs to attribute data, the Kappa analysis was performed to confirm the measurement system. An experiment was conducted by three pathology nurse practitioners (A, B, and C) with 10 testing specimens that include three accepted and seven rejected specimens and two duplications, to calculate the Kappa coefficient. The Kappa analysis showed that the measurement results between nurse practitioners $\mathrm{A}$ and $\mathrm{B}$ were fairly consistent with the Kappa coefficients $>0.75$. However, the measurement consistency between nurse practitioners $\mathrm{A}$ and $\mathrm{C}$ as well as between $\mathrm{B}$ and $\mathrm{C}$ needed improvement. The team also conducted an agreement analysis of the measurement results and the true values of the testing specimens by Minitab application. The assessment agreement percentage of nurse practitioners $\mathrm{A}, \mathrm{B}$, and $\mathrm{C}$ 
Table 3. Definition of the process output

\begin{tabular}{lllll}
\hline $\begin{array}{l}\text { Process } \\
\text { output }(y)\end{array}$ & Rejection rate & $\begin{array}{l}\text { Number of lost } \\
\text { specimens }\end{array}$ & $\begin{array}{l}\text { Number of } \\
\text { specimen } \\
\text { labeling errors }\end{array}$ & $\begin{array}{l}\text { Number of incomplete } \\
\text { discrepant specimen } \\
\text { requisition form }\end{array}$ \\
\hline \multirow{3}{*}{ Unit } & Number of specimens rejected & $\begin{array}{l}\text { Difference between } \\
\text { number of original } \\
\text { requisition forms and } \\
\text { number of } \\
\text { received specimens }\end{array}$ & Number of fault & Number of fault \\
\cline { 2 - 5 } & Number of specimens received & $\begin{array}{l}\text { Continuous } \\
\text { monitoring }\end{array}$ & $\begin{array}{l}\text { Tabular } \\
\text { computing }\end{array}$ & Tabular computing \\
\hline Measurement & Tabular computing & 0 & 0 & 0 \\
\hline Target & $0 \%$ & &
\end{tabular}

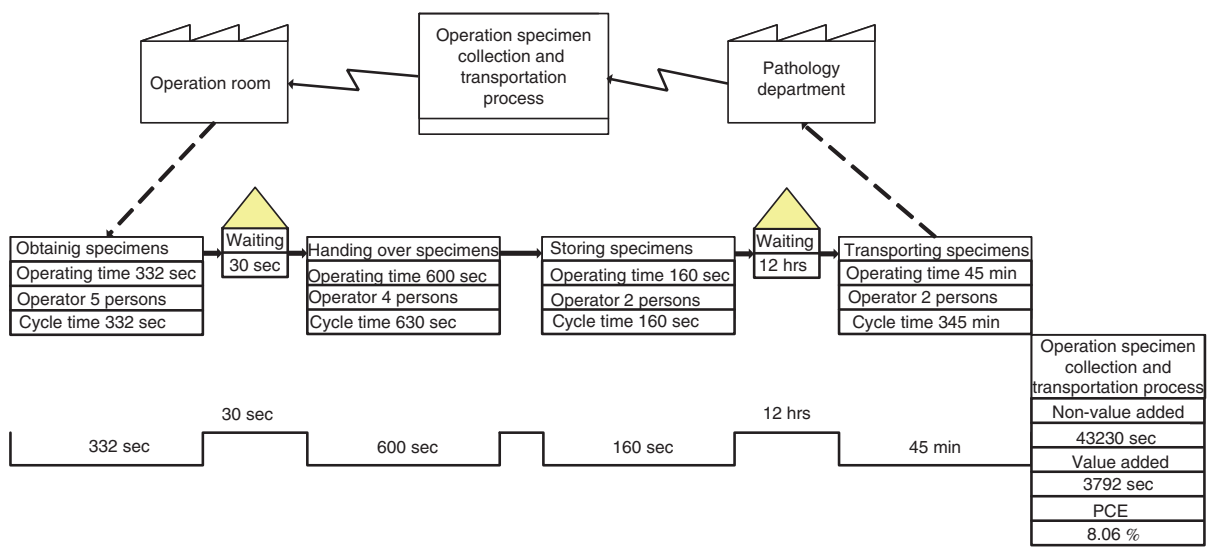

Figure 3. VSM for specimen collection and transportation (Before improvement).

were $95 \%, 95 \%$, and $85 \%$, respectively. The percentage indicates that the measurement results of nurse practitioners $\mathrm{A}$ and $\mathrm{B}$ demonstrated high consistency with the corresponding true values, whereas those of nurse practitioner $\mathrm{C}$ needed consistency improvement. After appropriate trainings, the consistency of nurse practitioner $\mathrm{C}$ was improved. The measurement system was then considered acceptable.

Next, a data collection plan was developed to collect the process output ( $y$ ) related data. The specimen rejection rate was $0.92 \%$. The specimen rejection rate is defined as the total number of the adverse events, including specimen labeling error, incomplete specimen requisition form, missing specimen or requisition form, inconsistency between the specimen collected and specified in the requisition form, difference between the numbers of original requisition forms, divided by the number of specimens received. The team members consensually set the goal to reduce specimen rejection rate by $50 \%$ to $0.45 \%$.

Finally, the project team created a VSM (Figure 3) to lay out the process between specimen retrieval from the patient and processing in the pathology lab in terms of time 
spent on each procedure. The process primarily involves specimen retrieval, verification, preservation, transportation, and receipt confirmation, where the VA and NVA works consumed 3,792 and 43,230 s, respectively, and the PCE was $8.06 \%$ before improvement (Figure 3). PCE lower than $10 \%$ indicates that the efficiency of process needs improvement.

\subsection{Analyze Phase}

The team analyzed the rejected specimens through proper use of tools to determine possible root causes and to identify the critical causes responsible for the rejection rate. According to the data collected at the measure phase, specimen labeling errors and incomplete specimen requisition forms were the major causes of specimen rejection. Through interviewing the healthcare providers directly involved in the specimen handling process, the project team identified the contributing factors for the major causes, which included lack of discipline in completing surgical records, lack of immediate double check of data accuracy, and lack of inspection mechanism as well as insufficient labor force.

Based on Figure 3, a summary of the transportation process of pathology specimen is listed in Table 4. The waiting time between specimen preservation in a refrigerator and delivery to the pathology department is the major cause of the poor performance of PCE (Table 4). Before the specimens reach the pathology department, they are usually stored in the refrigerator and delivered only twice a day, after 8 am and $12 \mathrm{pm}$. The average of such waiting time is $12 \mathrm{~h}$. The long waiting time can result in possible delay in diagnosis; therefore, increasing the number of delivery times can be a solution to reduce waiting.

The specimen rejection rate revealed the existence of failures in the process; thus, the project team applied HFMEA to analyze the potential failure modes. After referring to the current specimen collection and transportation process and interviewing related personnel, the project team drew the full description of the process (Figure 4). A hazard analysis was performed to evaluate all possible failure modes, and these results were examined by the logic of decision tree to determine whether the sub-processes should further continue. A few exemplar HFMEA tables are shown in the Appendix. Table 5 presents a summary of the major failure modes of each sub-process that cause specimen rejection. These major failure modes provide specific directions for the improve phase.

\subsection{Improve Phase}

On the basis of the analysis results obtained from the analysis phase, the project team developed improvement solutions for implementation. The approved solutions included the following measures.

The first stage:

- Set up required fields on the pathology requisition form and develop policies to ensure that the detailed specimen description, such as the anatomical part of the body and specimen number, is correctly recorded.

- Require signatures of both the person delivering the specimen and the doctor in charge to identify the responsibility of specimen error. 
Table 4. Summary of the handling process of surgical specimens

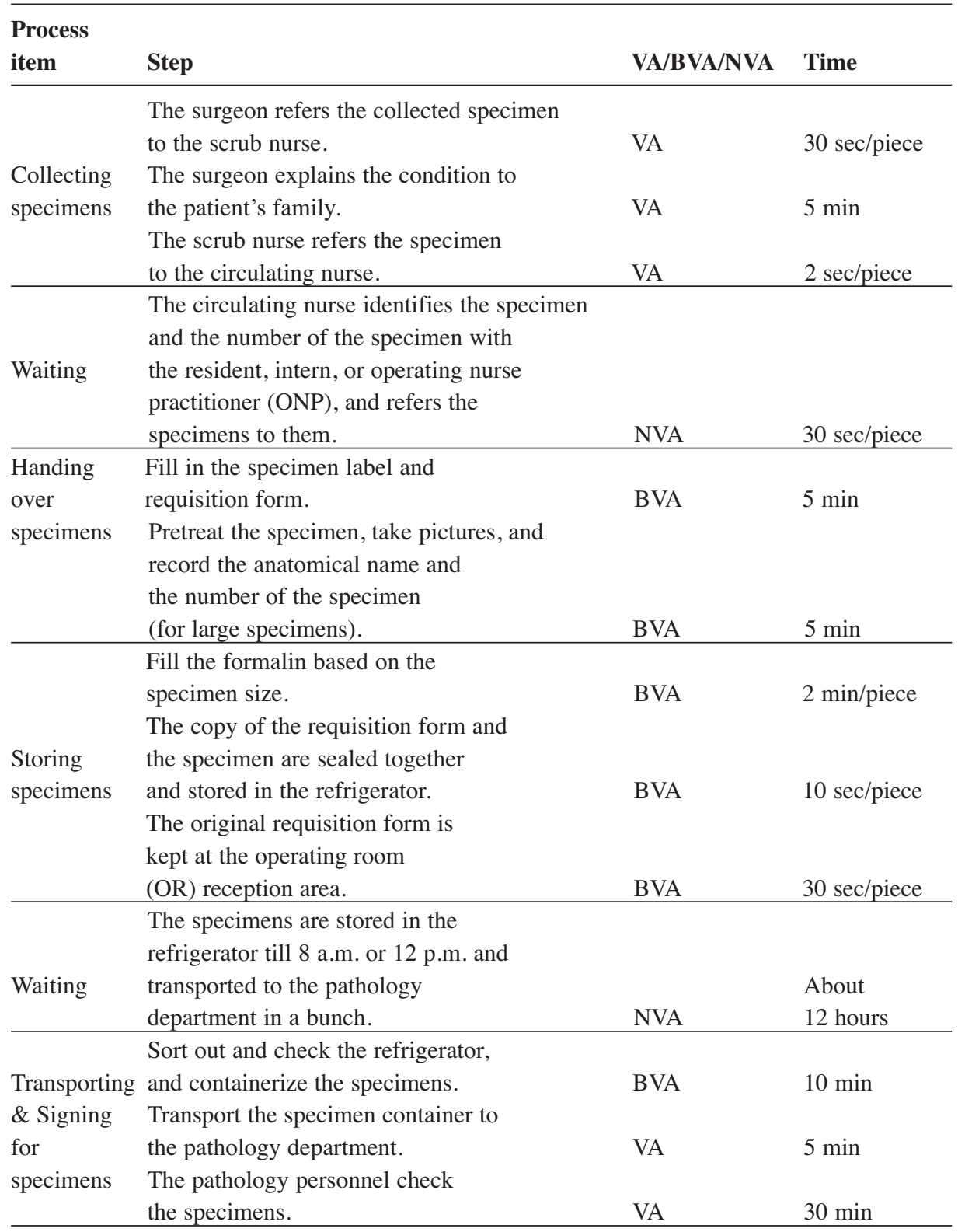




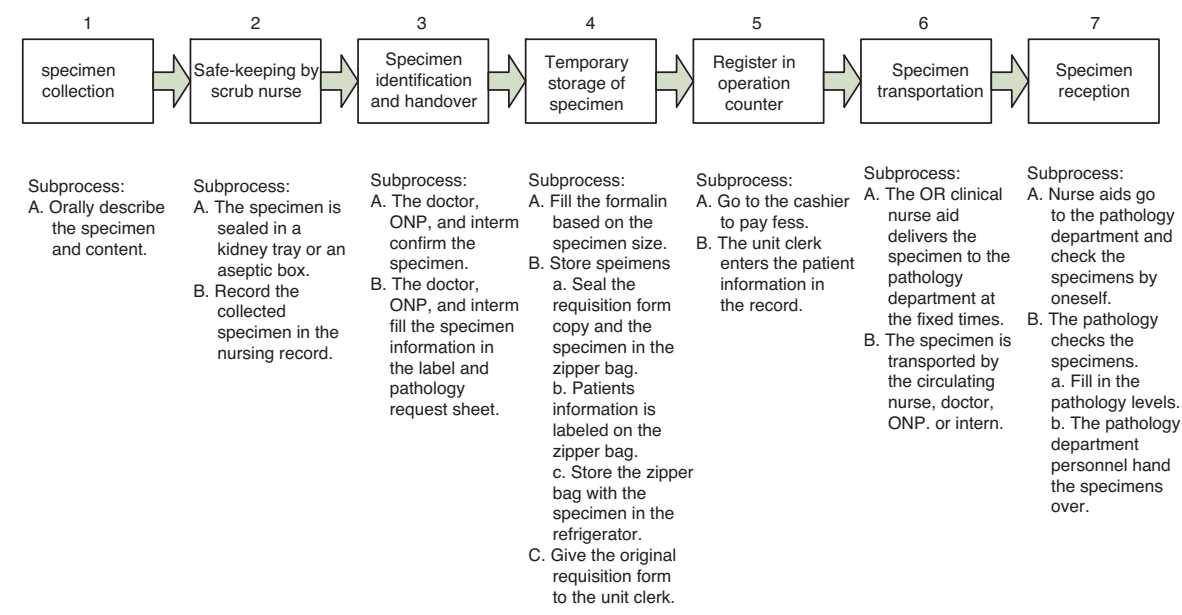

Figure 4. HFMEA procedure for the specimen handling process.

- Modify standard operation procedures, standardize specimen labeling, and promote timely specimen handling and provide appropriate training for the medical personnel involved in the process.

- Specify the methods for counting and packaging specimens to ensure the accuracy of the specimen number and the integrity of the specimen.

- Use security stickers to package the specimen and ensure that the specimen is secured.

- Change the pick-up schedule for the nurse assistant in the OR from two times a day to three times a day $(8 \mathrm{am}, 12 \mathrm{pm}$, and $5 \mathrm{pm})$ to reduce the specimen average storage/waiting time to $8 \mathrm{~h}$.

- Replace the existing specimen storage refrigerator to avoid stacking of specimens.

- Establish the appropriate mechanisms for specimens return to shorten and simplify the process. Rejected specimens are not sent back to the requesting units to avoid adverse events during transportation.

The second stage:

Information like data of patients and specimens should be recorded in the transporting process. However, this might increase the recording error and time in handwriting. Many studies suggested to use new technologies (e.g., barcode reading) to minimize the possibility of human error, and education on medical safety $[11,15]$. To reduce these undesirable drawbacks, a "Surgery Specimen Management System (SSMS)" was established, and a bar code technology was used to track all processes. The detailed system procedure is presented as below:

1. Login the SSMS and fill in the requisition form. The e-requisition form is designed based on the original hard copy form. The operation information, such as the patient's name, the chart number, the surgical procedure, and the surgical site, is automatically entered into the e-requisition form. Furthermore, some items are set as the required. If one required filed is omitted, the system will show the alert window to remind the user. 


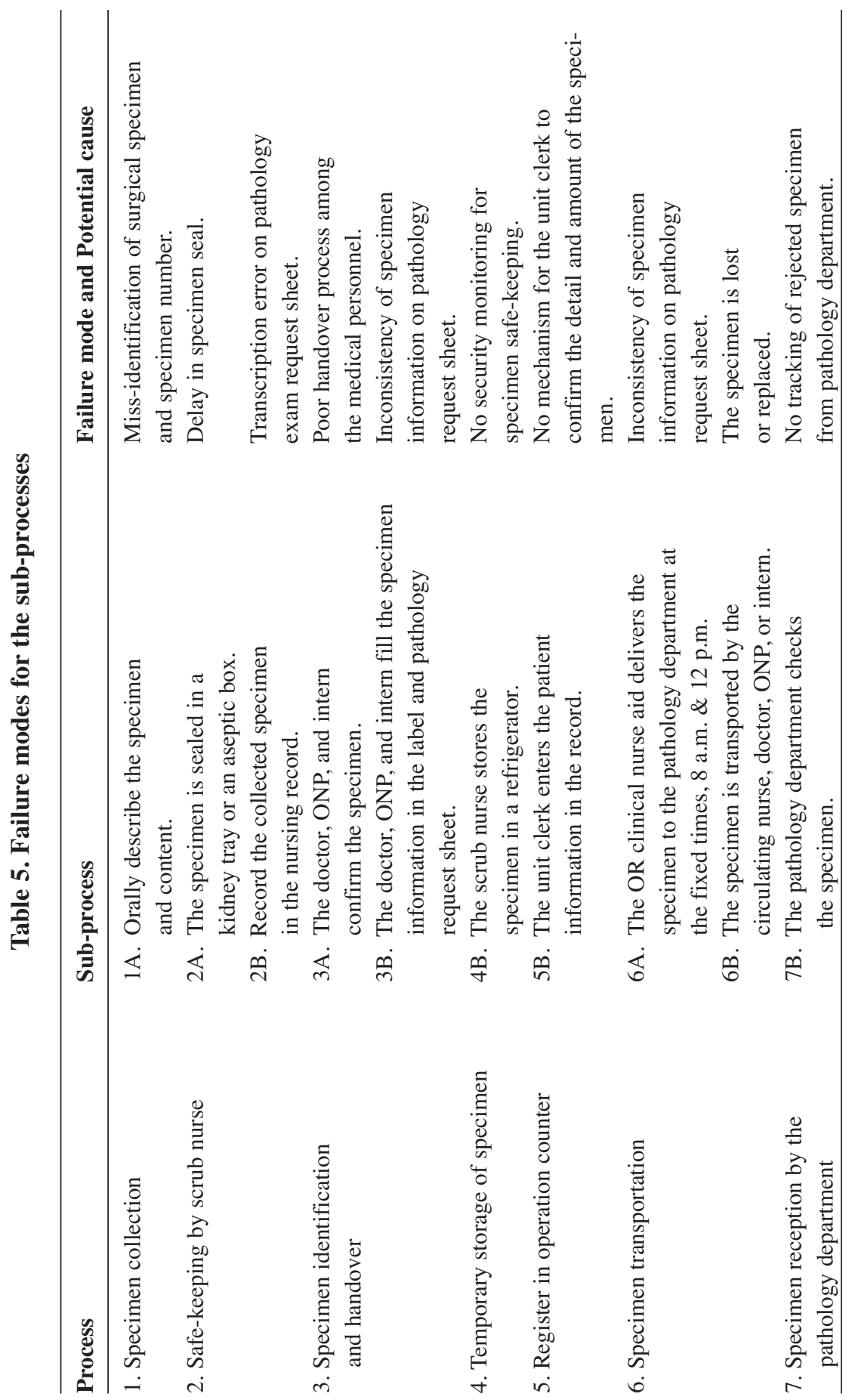


2. Auto-print the information label. After completing the e-requisition form, the requisition hard copy and the major specimen information is printed out on labels automatically, including the patient's name, the specimen site, number, and inspector, and the specimen bar code tags are created. The bar code tag's information is linked to e-requisition form, and the tags are attached to the specimen cans and sealed bags.

3. Inbound management. Set a designated refrigerator and only attending physicians, resident and nurses are authorized to access this refrigerator. When they put the specimen in this refrigerator, they need to log in the system and scan the bar code of the sealed bag to complete the specimen inbound. When the bar code is scanned, the inbound time is automatically recorded in the system.

4. Outbound management. Only the operation nurse has this authority. The operation nurse logs in the system and scans all required specimen bar codes to execute the outbound operation. These specimens are put into a specified delivery box with the operation head nurse's confirmation before being delivered to the pathology department.

5. The specimen management platform. After the specimen information is recorded, all related departments can inquire and view the specimen condition in real time through the information system.

6. Confirm and sign for specimens. After the pathology department personnel receive the specimen, they login the system and scan the bar code on the sealed bag to sign for receiving the specimen and check its records. In case unusual events occur, these data will be recorded and the system will alert relevant personnel.

7. Quality management. To strengthen quality management, the system automatically generates 20 quality indicators, such as daily number of specimen inspection, daily number of rejected specimens, and transportation time, for the operating room, pathology department, and surgeon.

A partial pilot implementation of these approved improvement measures was conducted before the comprehensive implementation. After a month of implementation, the specimen rejection rate significantly dropped to $0 \%$, indicating that the improvement measures can actually benefit the process and achieve desired goal. The waiting time also decreased from $12 \mathrm{~h}$ to $8 \mathrm{~h}$.

\subsection{Control Phase}

According to the 2013 annual report of the Taiwan Joint Commission in charge of the Taiwan Patient Safety Reporting System [38], in the specimen handling process, 59.6\% of the surgical specimen errors occurred before transporting to the pathology for examination, and $45.2 \%$ of them are related to specimen labelling, including $23.6 \%$ of missing label and $21.6 \%$ of wrong label.

A significant decrease in the specimen rejection rate occurred after the implementation of the improvement measures (Figure 5). The rejection rate was below 0.4\% from April 2011 to June 2012. The project team then started the second stage of 


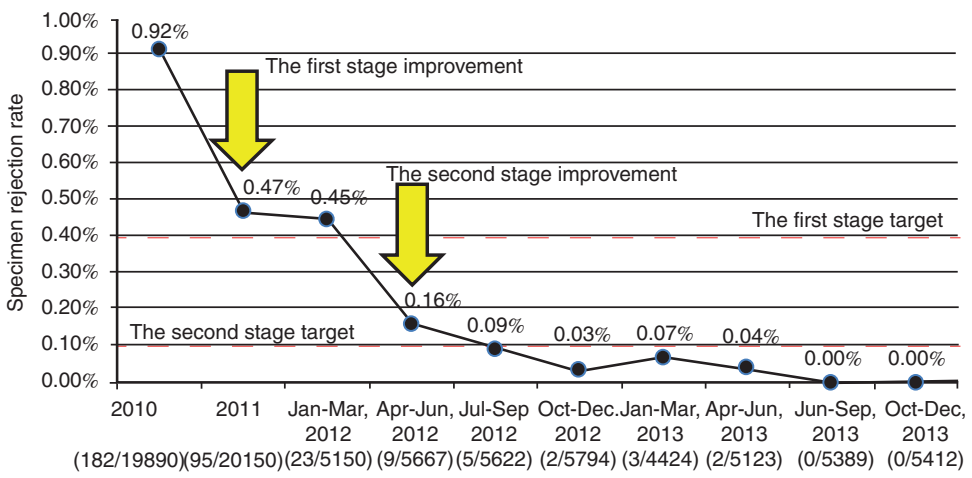

Figure 5. Improvement run chart of the surgical specimen rejection rate

improvement measures after July 2012 and set a rejection rate target of $0.1 \%$. The average rejection rate after July 2012 also achieved the target. The project team further achieved the goal of zero specimen rejection rate in July, 2013. Many rejection causes, such as specimen labeling errors, incomplete specimen requisition form, missing specimens or requisition form, inconsistency between the specimen and requisition form, difference between number of original requisition forms and number of received specimens are all decreased to zero in July, 2013 (Table 6).

Proper trainings were widely provided to the healthcare personnel involved in the specimen handling process. The responsibilities of the personnel in charge of each process were clearly defined, and the standard operation procedure was strictly followed to achieve effective improvement. Finally, the project team transferred the improved process to the process owners to sustain the results and continue monitoring the process.

\subsection{Benefit Analysis}

Reducing the error risk in specimen handling process is imperative for patient safety. By decreasing the specimen rejection rate, the potential health risk cost can be reduced. Considering the assumption that the average yearly specimen rejections are 150 and each rejection costs $\$ 12.7$, which includes medical supply fee, transportation and labor cost of transportation and examination, a yearly saving of cost and rejection handling time of $\$ 1,900$ and $175 \mathrm{~h}$, respectively, can be achieved. The cost of handling the rejected specimens is low, but it might lead to malpractice litigations if the specimens are mislabeled or lost.

The average compensation for medical malpractice was USD \$7,500 for errors involving specimen mislabeling and transportation problem, based on an official statistics in 2004 [39]. In Taiwan, three major adverse events, including loss of specimens and allegedly switched specimens, led to malpractice as well as misdiagnosis. The average compensation for each event was USD $\$ 380,000$ and listed as the key issue of patient safety accreditation [40]. Furthermore, such events often 
Table 6. The surgical specimen rejection causes

\begin{tabular}{|c|c|c|c|c|c|c|c|c|c|c|}
\hline $\begin{array}{l}\text { Reject } \\
\text { Cause }\end{array}$ & Before & $\begin{array}{c}\text { Stage1 } \\
\text { Improvement }\end{array}$ & Improving & $\begin{array}{c}\text { Stage } 2 \\
\text { Improvement }\end{array}$ & & fter & & Mainten & lance & \\
\hline Time & 2010 & 2011 & $\begin{array}{c}2012 \\
\text { Jan-Mar }\end{array}$ & $\begin{array}{c}2012 \\
\text { Apr-Jun }\end{array}$ & $\begin{array}{c}2012 \\
\text { Jul-Sep }\end{array}$ & $\begin{array}{c}2012 \\
\text { Oct-Dec. }\end{array}$ & $\begin{array}{c}2013 \\
\text { Jan-Mar }\end{array}$ & $\begin{array}{c}2013 \\
\text { Apr-Jun }\end{array}$ & $\begin{array}{c}2013 \\
\text { Jul-Sep }\end{array}$ & $\begin{array}{c}2013 \\
\text { Oct-Dec }\end{array}$ \\
\hline $\begin{array}{l}\text { Specimen } \\
\text { labeling } \\
\text { errors }\end{array}$ & 94 & 53 & 6 & 3 & 1 & 0 & 3 & 1 & 0 & 0 \\
\hline $\begin{array}{l}\text { Incomplete } \\
\text { specimen } \\
\text { requisition } \\
\text { form }\end{array}$ & 45 & 22 & 5 & 0 & 0 & 2 & 0 & 0 & 0 & 0 \\
\hline $\begin{array}{l}\text { Difference } \\
\text { between } \\
\text { number of } \\
\text { original } \\
\text { requisition } \\
\text { forms and } \\
\text { number of } \\
\text { received } \\
\text { specimens }\end{array}$ & 15 & 10 & 1 & 1 & 0 & 0 & 0 & 0 & 0 & 0 \\
\hline $\begin{array}{l}\text { Missing } \\
\text { specimens }\end{array}$ & 8 & 5 & 3 & 1 & 3 & 0 & 0 & 1 & 0 & 0 \\
\hline $\begin{array}{l}\text { Inconsistency } \\
\text { between the } \\
\text { specimen and } \\
\text { requisition form }\end{array}$ & 12 & 3 & 3 & 1 & 1 & 0 & 0 & 0 & 0 & 0 \\
\hline $\begin{array}{l}\text { Requisition } \\
\text { form }\end{array}$ & 8 & 2 & 6 & 1 & 0 & 0 & 0 & 0 & 0 & 0 \\
\hline Total & 182 & 95 & 24 & 7 & 5 & 2 & 3 & 2 & 0 & 0 \\
\hline
\end{tabular}

damage the financial status and the image of the hospitals and healthcare staff as well as physician-patient relationship [40]. Therefore, it is highly important to actively engage in process analysis and improvement to totally eradicate such error.

The integrated DMAIC structure is helpful in creating a high-quality healthcare environment, improving satisfaction of patient and their family, and reducing the risks and disputes between patients and hospitals.

\section{DISCUSSION}

In the healthcare environment, all hospitals strive to provide a safe and quality environment for patients. Hospitals are facing all kinds of challenges every day, where no error is tolerated. This is why medical malpractice has been a main concern for all hospitals. The specimen handling process is critical for doctors to provide correct diagnosis. Any mistakes during the process may lead to misdiagnosis and improper treatment. Therefore, zero defect for the specimen handling process is the ultimate goal for all hospitals. Earlier studies typically applied single improvement methods such as Six Sigma, VSM, or HFMEA to improve the specimen handling process, while our study innovatively incorporates several quality management tools to conduct the process analysis and achieve better results. 
After the implementation of the project, the surgical pathology specimen safety of the hospital was improved tremendously. The specimen rejection rate (by the receiving department) was reduced from $0.92 \%$ to $0 \%$. The sign-out and surgical safety were also ensured, as proved in the previous studies $[10,14-15]$. On the other hand, adopting the barcode technology not only reduced medical errors but also promoted the patient safety [10,14-15]. However, few studies have integrated VSM/HFMEA into Six Sigma methodology to monitor the effectiveness of barcode technology-driven process reengineering. Moreover, we embedded the dynamic process in surgery specimen management system (SSMS) to record the information at each node and tracked specimen. The electronic information system can reduce the redundant transcription and prevent time-consuming paperwork. The innovation of our study is that the applied system is able to collect indices automatically and provide references for managers to monitor analyses, so that they can grasp the dynamics of specimens in real time through the intranet and provide a communication platform for related personnel. SSMS with the application of barcode technology can improve surgical specimen handling workflow and track the process in real time.

After implementation, we analyzed the time and cost saved and found that the cost saving from rejection handling, potential medical compensation, and other medical expenses per year was $\$ 1,900$. In addition, the incidents of medical dispute, erroneous diagnosis, and missing specimen can be more effectively prevented. The medical personnel can save $175 \mathrm{~h}$ per year in handling specimen rejections. The PCE was enhanced from $8.06 \%$ to $11.62 \%$.

\section{CONCLUSION}

Specimen handling is a complicated process and critical safety issue in hospitals. Few studies have analyzed the process of surgical specimen collection and transport. Our study applied the proactive risk analysis of HFMEA, VSM, and Six Sigma to provide useful information for remodeling and enhancing the surgical specimen handling process. The establishment of SSMS was proved to be effective in reducing human errors, thereby improving the safety and efficiency of surgical specimen handling. Our experience and strategy may be applied to inter-hospital specimen transportation in the future. Though the risk has been significantly reduced in the study hospital after the intervention, due to the different potential risks of individual hospitals, the risk analysis for the study hospital may not apply to others; this is a limitation of the current study. However, the analysis tools and process re-engineering of this study can be the reference for other hospitals.

\section{ACKNOWLEDGEMENTS}

The authors would like to acknowledge the advice from the operating room, Departments of Pathology, and Information Technology of Cathay General Hospital, Taipei, Taiwan.

\section{CONFLICT OF INTEREST}

The authors indicated no potential conflicts of interest. 


\section{REFERENCES}

[1] Heuvel J, Does RJ, Verver J P S. Six Sigma in healthcare: lessons learned from a hospital, International Journal of Six Sigma and Competitive Advantage, 2005, 1(4):380-388.

[2] Van der Meulen F, Vermaat T, Willems P. Case study: an application of logistic regression in a Six Sigma project in health care, Quality Engineering, 2011, 23(2):113-124.

[3] Lazarus IR, Stamps B. The promise of Six Sigma: getting better faster, Extra Ordinary Sense, 2002,3:3-29.

[4] Murugappan M, Keeni G. Quality Improvement-The Six Sigma Way. First Asia-Pacific Conference on Quality Software Proceedings, 2000, 248-257.

[5] Feng Q, Antony J. Integrating DEA into Six Sigma methodology for measuring health service efficiency, Journal of the Operational Research Society, 2010, 61:1112-1121.

[6] Tang LC, Goh TN, Lam SW, Zhang CW. Fortification of Six Sigma: Expanding the DMAIC toolset, Quality and Reliability Engineering International, 2007, 23(1):3-18.

[7] Teichgräber UK, de Bucourt M. Applying value stream mapping techniques to eliminate non-valueadded waste for the procurement of endovascular stents. European Journal of Radiology, 2011, 81(1):e47-52.

[8] Dehnavieh R, Ebrahimipour H, Molavi-Taleghani Y, Vafaee-Najar A, Noori Hekmat S, Esmailzdeh H. Proactive risk assessment of blood transfusion process, in pediatric emergency, using the Health Care Failure Mode and Effects Analysis (HFMEA). Global Journal of Health Science, 2014, 7(1):322-331.

[9] Arnheiter ED, Maleyeff J. The integration of lean management and Six Sigma. The TQM Magazine, 2005, 17(1):5-18.

[10] David G, Hicks. Standardization of Tissue Handling from the OR to the laboratory. AORN Journal, 2014, 99(6):810-813.

[11] Minato H, Fukushima M, Nojima T, Nakano M. Specimen misidentification in pathology laboratory: trends and measures. Journal of Clinical Pathology, 2013, 8:751-759.

[12] Wagar EA. Specimen labeling errors: A Q-probes analysis of 147 clinical laboratories. Arch Pathol Lab Med, 2008, 132:1617.

[13] Raouf E, Nakhleh. Patient Safety and Error Reduction in Surgical Pathology. Arch Pathol Lab Med, 2008, 132:181-185.

[14] Graybill D, Ercole P. RP implementation: specimen management. AORN Journal, 2014, 625-633.

[15] Trask L, Tourmas E. Barcode Specimen Collection Improves Patient Safety. Medical Laboratory Observer, 2012, 44(4):44-45.

[16] Trask L. Barcode specimen collection. It's fast. It's easy. It can stops errors for good. Medical Laboratory Observer, 2014, 46(12):20-21.

[17] Hellensead SC, Lockwood WB, Elin RJ. Errors in Pathology and Laboratory Medicine: Consequences and Prevention. Journal of Surgical Oncology, 2004, 88(3): 161-181.

[18] Bart JT. Clinical Laboratory Utilization: Rationale in: Davis B, Mass D, Bishop. Principles of Clinical Laboratory Utilization and Consultation, 1999, Philadelphia, PA: Saunders: 6.

[19] Wiwanitkit V. Types and Frequency of Pre-analytical Mistakes in the First Thai ISO 9002:1994 Certified Clinical Laboratory, a 6-month Monitoring. BMC Clinical Pathology, 2001, 1(5):5-9.

[20] Alsina MJ, Álvarez V, Barba N, Bullich S, Cortés M, Escoda I, Matinez-Brú C. Preanalytical Quality Control Program - an Overview of Results (2001-2005 summary). Clinical Chemistry and Laboratory Medicine, 2008, 46(6):849-854.

[21] Pande P, Neuman R, Cavanagh R. The Six Sigma Way: How GE, Motorola and Other Top Companies are Honing Their Performance, New York: McGraw-Hill, 2000.

[22] Harry M, Schroeder R. Six Sigma: The Breakthrough Management Strategy Revolutionizing the World's Top Corporations, New York: Doubleday, 1999. 
[23] Su CT, Hsiao YH, Liu YL. Enhancing the fracture resistance of medium/small-sized TFT-LCDs using the Six Sigma methodology. IEEE Transactions on Components Packaging and Manufacturing Technology, 2012, 2(1):149-164.

[24] George M L, Rowlands D, Price M, Maxey J. The Lean Six Sigma Pocket Toolbook: A Quick Reference Guide to 100 Tools for Improving Quality and Speed, McGraw-Hill, New York, 2004.

[25] Grove AL, Meredith JO, Macintyre M, Angelis J, Neailey K. Lean implementation in primary care health visiting services in National Health Service UK. Quality and Safety in Health Care, 2010, 19(5) e43.

[26] Mazur LM, Chen SJ. Understanding and Reducing the Medication Delivery Waste via Systems Mapping and Analysis. Health Care Management Science, 2008, 11(1):55-65.

[27] Carter PM, Desmond JS, Akanbobnaab C, Oteng RA, Rominski SD, Barsan WG, Cunningham RM. Optimizing Clinical Operations as Part of a Global Emergency Medicine Initiative in Kumasi, Ghana: Application of Lean Manufacturing Principals to Low-resource Health Systems. Academic Emergency Medicine, 2012, 19(3):338-347.

[28] DeRosier J, Stalhandske E, Bagian JP, Nudell T. Using health care Failure Mode and Effect Analysis: the VA National Centre for Patient Safety's prospective risk analysis system. The Joint Commission Journal on Quality Improvement, 2002, 28(5):248-267.

[29] Krouwe JS. An improved failure mode effects analysis for hospitals. Archives of Pathology and Laboratory Medicine, 2004, 128(6):663-667.

[30] Gilchrist M, Franklin BD, Patel JP. An outpatient parenteral antibiotic therapy (OPAT) map to identify risks associated with an OPAT service. Journal of Antimicrobial Chemotherapy, 2008, 62(1):177-183.

[31] Joint Commission on Accreditation on Healthcare Organization, Revisions to Joint Commission standards in support of patient safety and medical/health care error reduction, Joint Commission on Accreditation on Healthcare Organization, Oakbrook Terrace, 2002.

[32] Hambleton M. Applying root cause analysis and failure mode and effect analysis to our compliance programs. Journal of Health Care Compliance, 2005, 7(2): 5-13.

[33] Kunac DL, Reith DM. Identification of priority for medication safety in neonatal intensive care. Drug Safety, 2005, 28(3):251-261.

[34] Cheng CH, Chou CJ, Wang PC, Lin HY, Kao CL, Su CT. Applying HFMEA to prevent chemotherapy errors. Journal of Medical Systems, 2012, 36(3): 1543-1551.

[35] Vélez-Díaz-Pallarés M, Delgado-Silveira E, Carretero-Accame ME, Bermejo-Vicedo T. Using Healthcare Failure Mode and Effect Analysis to reduce medication errors in the process of drug prescription, validation and dispensing in hospitalised patients. BMJ Quality \& Safety, 2012. doi:10.1136/bmjqs-2012-000983

[36] Kuo RJ, Wu YH, Hsu TS. Integration of fuzzy set theory and TOPSIS into HFMEA to improve outpatient service for elderly patients in Taiwan. Journal of the Chinese Medical Association, 2012, 75(7):341-348.

[37] Collins CM, Elsaid KA. Using an enhanced oral chemotherapy computerized provider order entry system to reduce prescribing errors and improve safety. International Journal for Quality in Health Care, 2011, 23(1):35-43.

[38] Taiwan Joint Commission on Hospital Accreditation. Hospital laboratory test and pathology biopsy event. Taiwan Patient-safety Reporting system Annual Report ,Taiwan, 2013,63-68.

[39] Compensation for medical malpractice.2004. http://health.gov.taipei/Default. aspx?tabid= 417\&mid=537\&itemid=15318. Accessed June 1, 2015.

[40] Medical dispute with surgical specimen misplace. 2015.http://news.ltn.com.tw/news/ life/paper/859318. http://news.ltn.com.tw/news/focus/paper/503123. Accessed June 1, 2015. 


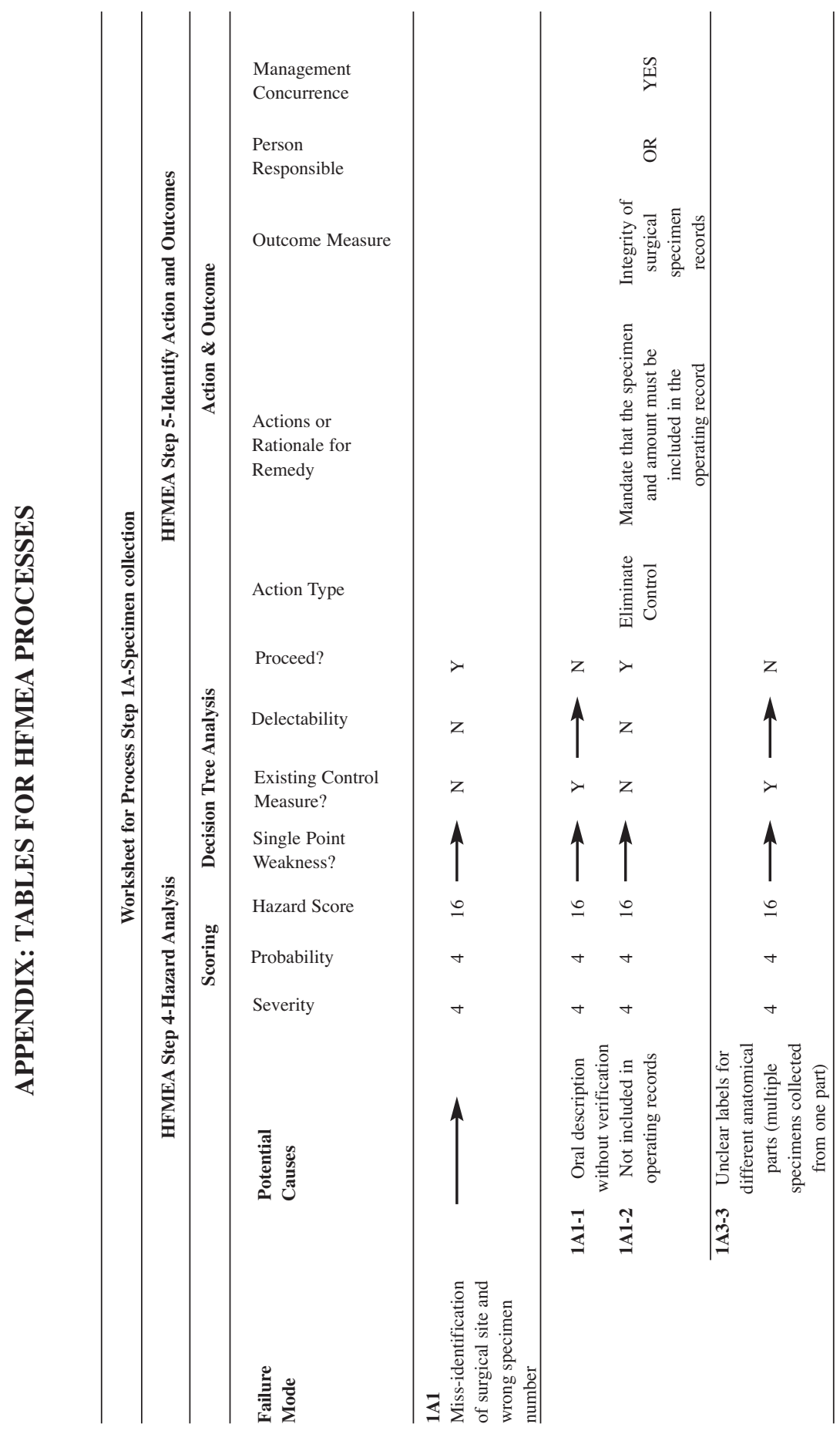




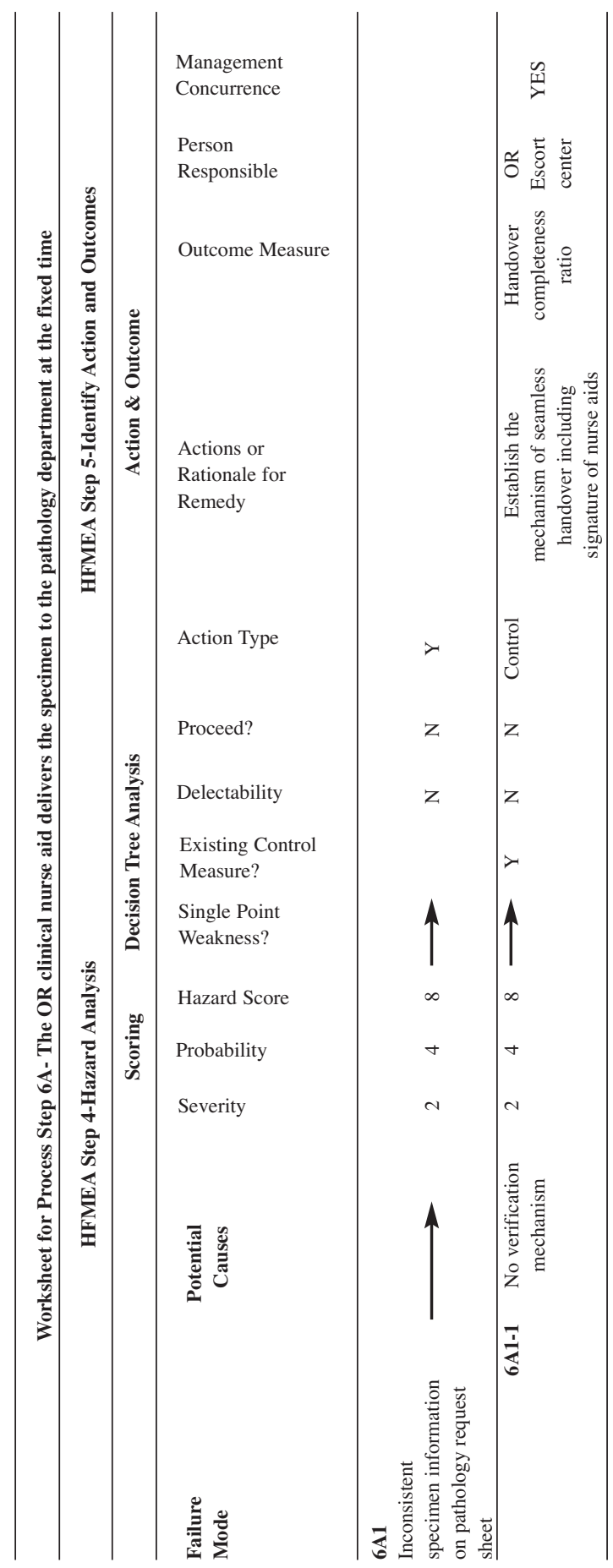




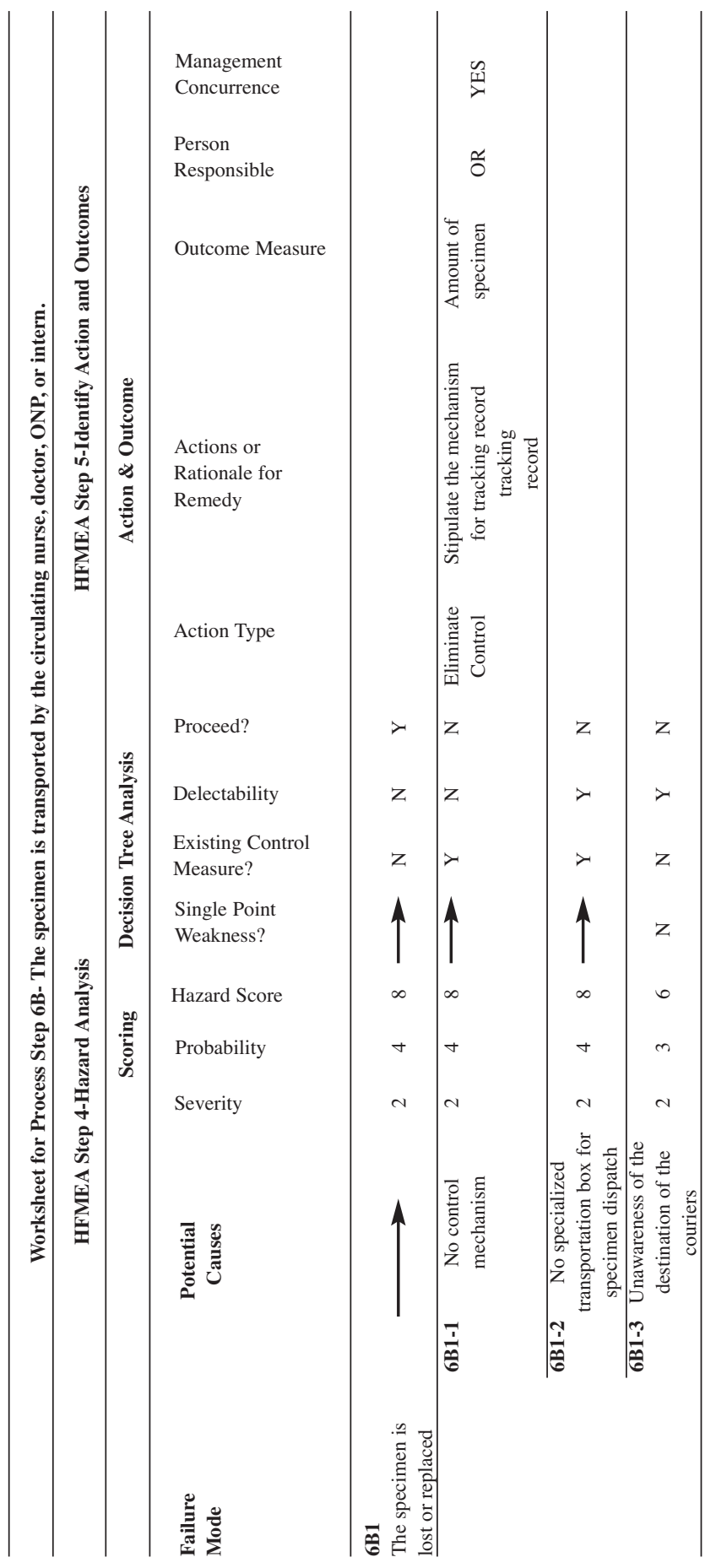




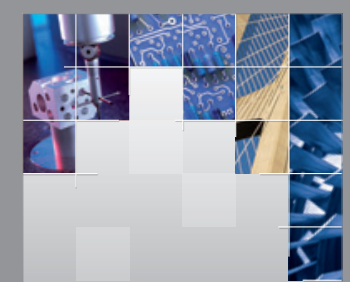

\section{Enfincering}
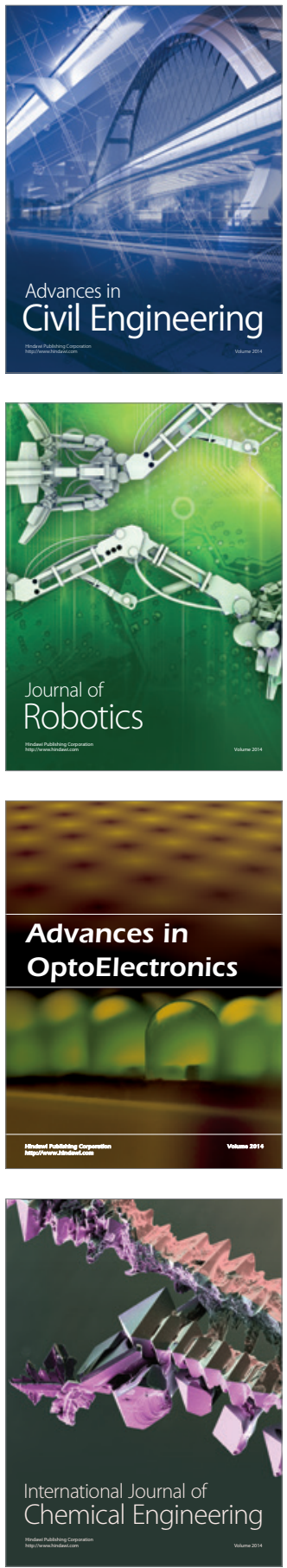

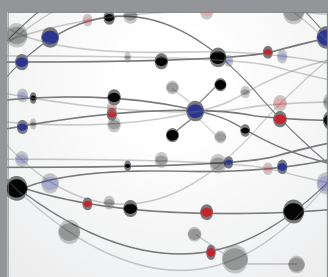

The Scientific World Journal

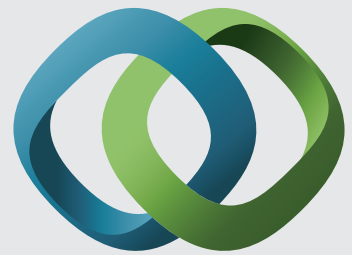

\section{Hindawi}

Submit your manuscripts at

http://www.hindawi.com
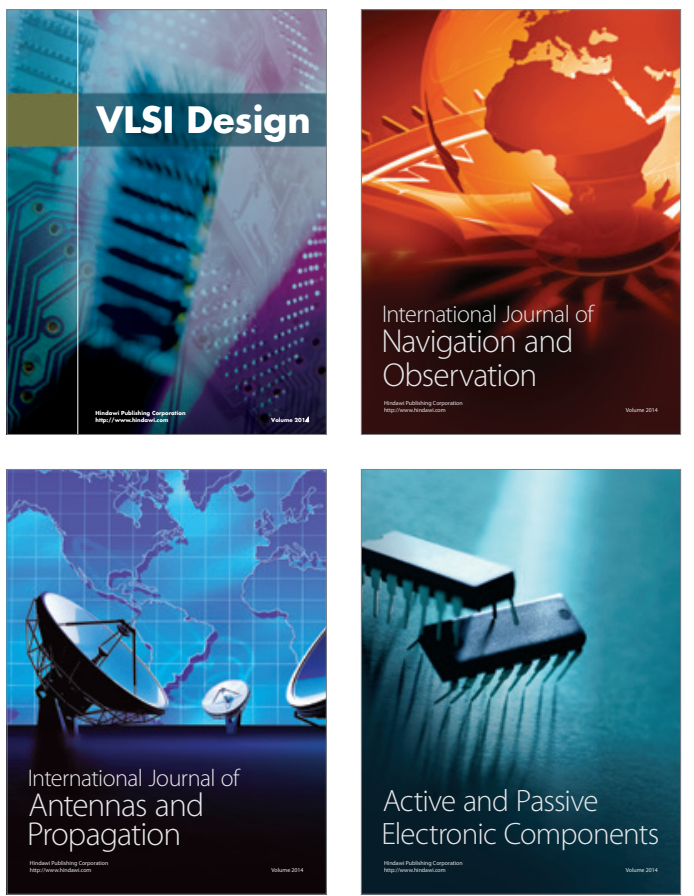
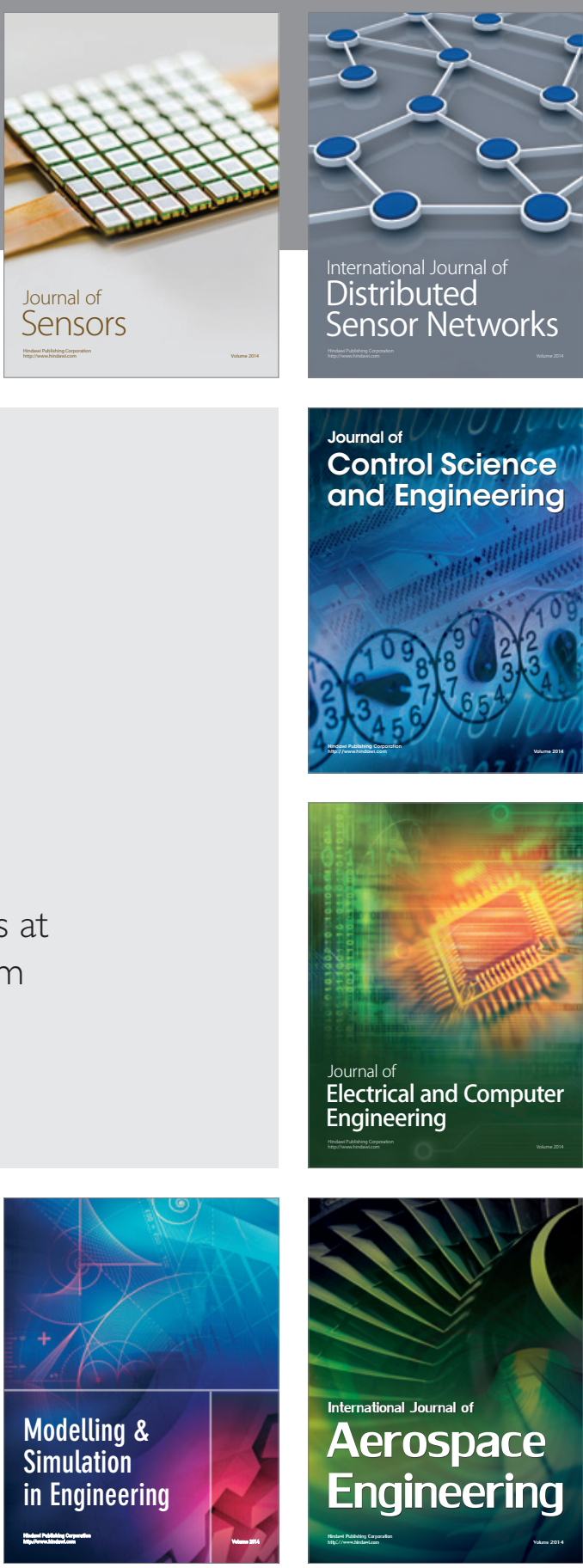

International Journal of

Distributed

Sensor Networks

Journal of

Control Science

and Engineering
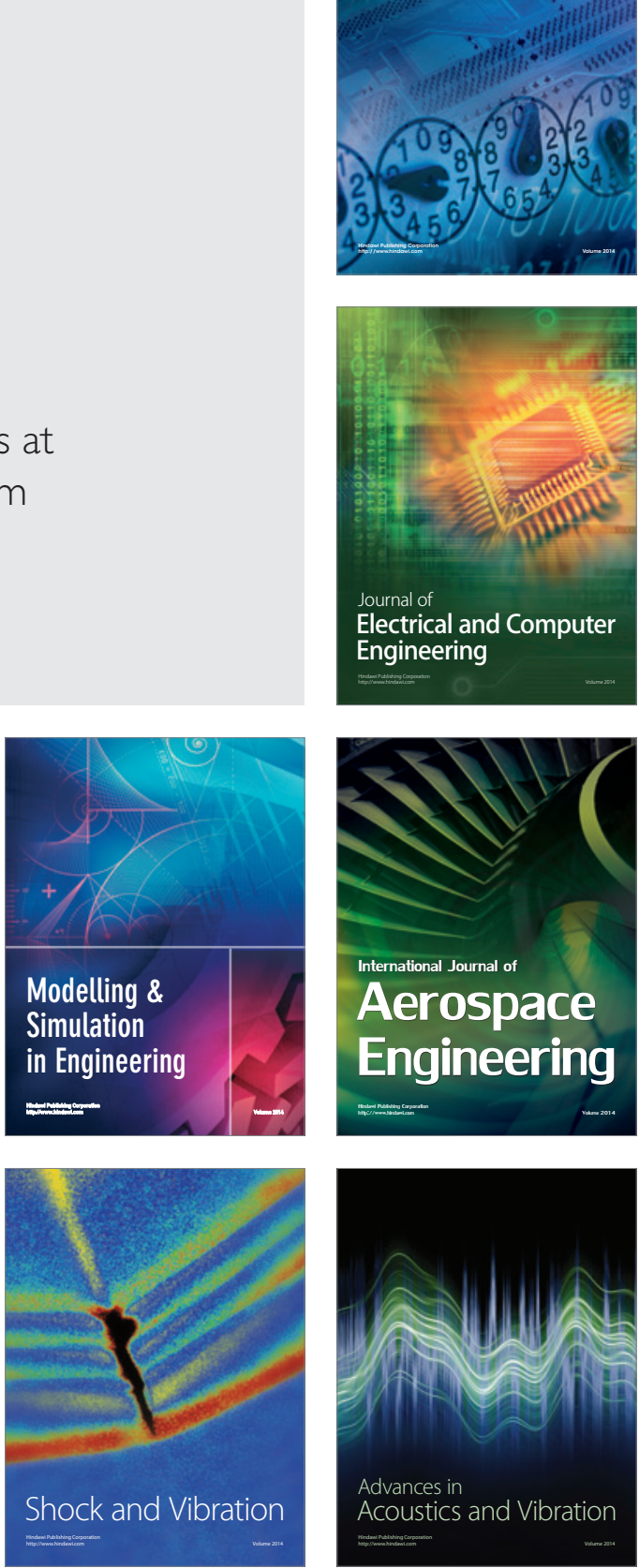